\title{
Diverse origin of Plasmodium falciparum in northwest Ecuador
}

\author{
Claudia A. Vera-Arias ${ }^{1}$, L. Enrique Castro², Javier Gómez-Obando ${ }^{3}$ and Fabián E. Sáenz ${ }^{* *}$
}

\begin{abstract}
Background: Ecuador plans to eliminate malaria by 2020, and the country has already seen a decrease in the number of cases from more than 100,000 in 2000 to only 618 in 2015. Around 30\% of malaria infections in Ecuador are caused by Plasmodium falciparum. Most malaria population genetics studies performed in Latin America, especially in the Pacific Coast, indicate a high clonality and a clear structure of P. falciparum populations. It was shown that an outbreak of $P$. falciparum in northwest Ecuador was the result of a clonal expansion of parasites circulating at low levels in the country or re-invading Ecuador from neighbouring territories. However, general characteristics of $P$. falciparum circulating in the northwest coast of Ecuador have not been determined. The main goal of this study was to genetically characterize the population structure of P. falciparum in coastal Ecuadorian localities bordering with Colombia.
\end{abstract}

Methods: Molecular investigation of 41 samples collected from 2013 to 2016 in San Lorenzo County, northwest Ecuador was performed using seven neutral microsatellite markers.

Results: The genetic population structure of P. falciparum in northwest Ecuador is clearly defined as three different genetic groups previously reported in Ecuador, Peru and Colombia.

Conclusions: The limited number of P. falciparum clonal types that are circulating in northwest Ecuador, are related to ancestral parasite clonal lineages reported in the Pacific Coast. These parasites could be a product of migration from neighbouring regions or residual clonal types circulating in the country in low proportions. Studies of the genetic characterization of $P$. falciparum in eliminating areas help determine the possible origin of parasites in order to create strategies to prevent the entrance of new lineages and achieve local elimination of malaria.

Keywords: Malaria, Plasmodium falciparum, Microsatellites, Genetic structure, Ecuador

\section{Background}

Malaria is present in 21 countries of Latin America, and about 126.8 million people were at risk of the disease in 2016 in the region. Plasmodium falciparum was responsible for approximately $30 \%$ of the reported malaria cases in the region [1-5]. Ecuador is one of the eight countries of the region with capacity to eliminate malaria by 2020 [1]; indeed, the country has decreased the number of cases from more than 100,000 in 2000 to 618 in 2015, and 1279 in 2017 [1, 4, 6]. In Ecuador, the presence of malaria

\footnotetext{
*Correspondence: fsaenz213@puce.edu.ec

${ }^{1}$ Centro de Investigación para la Salud en América Latina, Facultad de Ciencias Exactas y Naturales, Pontificia Universidad Católica del Ecuador, Av. 12 de octubre 1076, Apartado: 17-01-2184, Quito, Ecuador

Full list of author information is available at the end of the article
}

is mostly restricted to the northwest coast and the Amazon region, where outbreaks of $P$. falciparum and Plasmodium vivax still occur $[6,7]$.

Genetic characterization of circulating malaria parasites in a specific area, especially in areas targeted for elimination, provide insights about the genetic connectivity of currently circulating populations to ancestral lineages and determine if left over residual historical parasite lineages are contributing to local transmission. This will also help to determine if new parasite lineages that have migrated from other regions are contributing to current malaria transmission. In addition, it can provide data about drug resistant alleles that may be relevant for targeting appropriate drugs for treatment or for mass drug administration [8-10]. Moreover, the level of diversity and its distribution provide insights 
into trends in parasite transmission and population history $[11,12]$.

Most malaria population genetics studies performed in Latin America indicate high clonality of $P$. falciparum populations [13-16]. Plasmodium falciparum from Ecuador, Colombia, Peru, Honduras, Brazil and Venezuela have undergone one or more bottleneck events in the recent past and current populations expanded from a limited number of $P$. falciparum ancestral lineages [7, 17-20]. Plasmodium falciparum populations in the region consist of a continuous mixture and reorganization of clonal lineages (genetically identical for a set of markers, but potentially variable for others [9]), mainly due to migration, even though the opportunities for outcrossing between the different lineages is limited because of low transmission $[9,13,17,21]$. In addition, P. falciparum from Latin America has had chloroquine (CQ) resistance since 1960 [20], as well as sulfadoxinepyrimethamine (SP) resistance [22, 23]. Recently, artemisinin (ART) resistance-related mutations have been reported in Guyana [20, 24, 25].

A molecular investigation of Peruvian P. falciparum population determined the presence of five clonal lineages in the country in 1999-2000. The Peruvian $P$. falciparum population consisted of A, B, C, D and E lineages distributed across the country. In the Amazon interior region, the five clonal lineages were present and in the northern Pacific coast only one lineage was reported (clonal lineage E). Each clonet had a specific drug resistant allelic profile; while all clonets reported $\mathrm{CQ}$ resistance, the clonets $\mathrm{D}$ and $\mathrm{E}$ had $d h f r$ and $d h p s$ alleles that confer SP sensitivity [21]. A P. falciparum outbreak in Tumbes (Pacific coast of Peru) during 2010-2012, had a genotype related to clonal lineage B $\left(\mathrm{B}_{\mathrm{v} 1}\right)$ but was unrelated to clonal lineage $\mathrm{E}$ (previously present in the same area) [15] and suggested that this outbreak was caused by clonal lineages from the Amazon region of Peru. Similarly, in Colombia the P. falciparum population has undergone a bottleneck event, showing low genetic diversity and low polyclonal infections [26]. The $P$. falciparum population structure consisted of four major clusters along the Colombian Pacific coast between 1999 and 2009 [26]. A different study in Colombia showed several multilocus haplotypes persist in multiple years between 2003 and 2010 in most of the country in Amazonas, Cordoba, Nariño and Valle [27]. Clonal lineage $B_{\mathrm{v} 1}$ (reported in Peru [14]) in the Amazon, two new clusters $F$ in Nariño, Valle and Cauca and cluster $E_{V 1}$ in Antioquia were reported [14, 16, 26-28]. Colombian parasites have reported CQ and $\mathrm{SP}$ resistance, in addition to an increase in the number of $p f m d r-1$ copies, carrying mefloquine (MQ) and quinine $(\mathrm{QN})$ resistance. Neither Peru nor Colombia has reported ART resistance or mutations in the Kelch 13 propeller domain [20, 22-25, 29].

The information about $P$. falciparum population genetic structure in Ecuador is limited. A molecular study of $P$. falciparum from Ecuador, during an outbreak in Esmeraldas city in the northwest of the country between November 2012 and November 2013, revealed that the parasites were the result of a clonal expansion of $P$. falciparum circulating at low levels or re-invading Ecuador from border countries [7]. The P. falciparum outbreak in northwest Ecuador had an identical microsatellite genotypic profile to $P$. falciparum E clonal lineages from the Peruvian Pacific coast. Interestingly, these parasites were related to a single historical isolate that was collected in the Ecuadorian coast in 1990 [7]. Esmeraldas outbreak samples carried CQ resistance (CVMNT haplotype) and dhfr and dhps alleles that were similar to E clonal type that were associated with SP sensitivity [7].

Molecular tools like neutral microsatellite markers (tandem repeats of motifs [18]) are a very important and powerful tool for the study of population structure because they can characterize and identify haplotypes and are extremely widespread in P. falciparum (2-3 kb throughout the genome) $[12,18,30]$. Neutral microsatellites are usually the markers of choice for $P$. falciparum population genetic analysis because these markers are not directly under selection and are able to show genetic signatures $[13-16,18,30]$. There is considerable amount of data using neutral microsatellite markers that have provided clues about genetic connectivity between parasite populations in Peru, Ecuador and Colombia.

The main goal of this study was to genetically characterize and geographically map the population structure of $P$. falciparum in northwest Ecuador (San Lorenzo county), between 2013 and 2016 using seven neutral microsatellites markers and compare them to previously characterized Ecuadorian parasites. In addition, Ecuadorian P. falciparum genotypes were compared to Peruvian and Colombian parasites.

\section{Methods \\ Ethics statement}

The parasite samples used in this study were obtained from the malaria surveillance program from the Ecuadorian Ministry of Health. The protocol was approved by the Ethical Review Committee of Pontificia Universidad Católica del Ecuador (approvals \#: CBE-016-2013 and 20-11-14-01). Written informed consent was provided by study participants and/or their legal guardians.

\section{Study sites}

The study analysed samples from communities in San Lorenzo county, northwest Ecuador (Fig. 1). These 


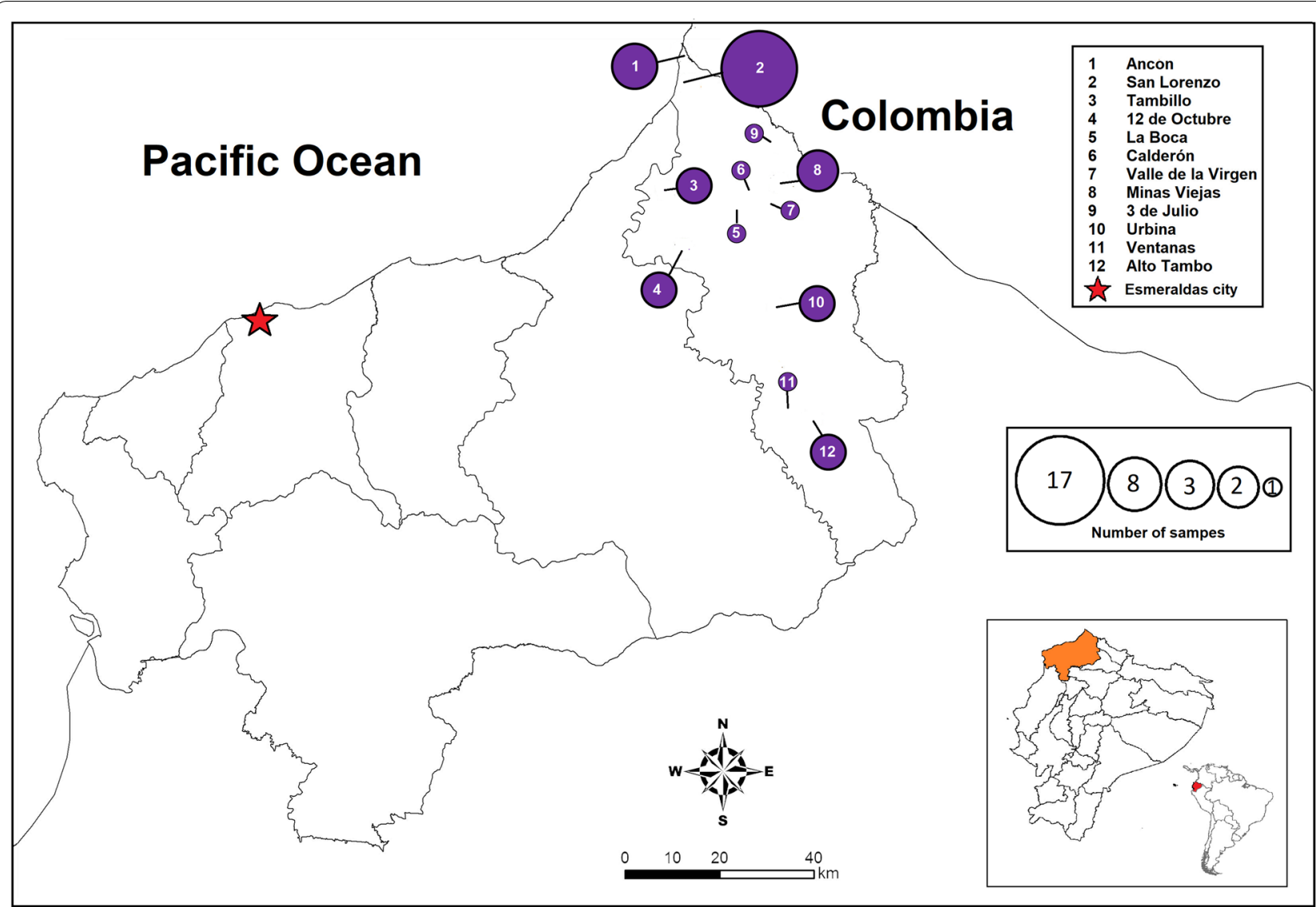

Fig. 1 Sample number and collection sites. All samples were collected in Esmeraldas province, San Lorenzo county, northwest Ecuador: there were 12 collection communities. Each sample collection location is represented with a purple circle. The circle diameter is proportional to the number of samples collected in each location

samples were compared to previously reported samples from the same province [7]. All the samples used in this study were collected between 2013 and 2016 (Fig. 1). Ecuadorian parasites were compared to previously reported Peruvian and Colombian parasites [21, 26].

\section{Samples and reference isolates}

Samples used in this study were collected from patients between January 2013 and March 2016 by the personnel of the Ministry of Health of Ecuador. A total of 41 blood samples (4 samples in 2013; 15 in 2014; 14 in 2015 and 8 in 2016) were collected in San Lorenzo county from patients who initially reported to be microscopically positive for $P$. falciparum infection, and from whom informed consent was obtained. The blood samples were collected by finger prick or by drawing peripheral whole blood and spotted on 3MM Whatman filter paper. Thirty-two samples from an outbreak in Esmeraldas city, between November 2012 and November 2013 and reported in Saenz et al. [7] were also included in the study. Fifty-six percent of the samples $(23 / 41)$ were collected by finger prick or by drawing peripheral whole blood and $44 \%$ of samples (18/41) were collected only by rapid diagnostic tests (RDT) with a positive result.

\section{DNA extraction and confirmation of infection}

DNA was isolated from all the samples (whole blood, filter paper or RDT) using a QIAamp DNA MINI KIT (QIAGEN Sample \& Assay Technologies, Germantown, USA). Plasmodium falciparum was confirmed by two different molecular methods: nested PCR using primers for $18 \mathrm{~S}$ ribosomal [31] and PET-PCR using photo-induced electron transfer fluorogenic primers [32].

\section{Microsatellite typing}

Genomic DNA was used for microsatellite characterization. Samples were genotyped for seven neutral microsatellite loci spanning six chromosomes (TA1, chromosome 6; Polyo, ch. 4; PfPk2, ch. 12; TA109, ch. 6; 2490, ch. 10; C2M34, ch. 2; C3M69, ch. 3) [12, 18, 33]. DNA was amplified using PCR previously described methods $[12,18,21,34,35]$. PCR products were labelled 
with fluorescent dyes (FAM or HEX) and were separated by capillary electrophoresis on an Applied Biosystems 3130xl genetic analyzer in South Korea at Macrogen Company. The fragments were scored using Peak Scanner Software V1.0 (Applied Biosystems Foster City, USA) [36].

\section{Statistical analysis}

Heterozygosity $(\mathrm{He})$ was estimated using the formula $H e=\frac{n}{n-1}\left(1-\sum_{i=l}^{k} p_{1}^{2}\right)$, and pairwise fixation indices (Fst), estimated using the formula $(\delta \mu)^{2}=\left(\mu_{A}-\mu_{B}\right)^{2}$, where $(\delta \mu)^{2}$ is the genetic distance and $\mu_{A}$ and $\mu_{B}$ are the average number of allelic size differences within population $\mathrm{A}$ and $\mathrm{B}$, respectively. He and Fst were calculated using Arlequin 3.5.1.2 software (CMPG, Swiss Institute of Bio-informatics, Lausanne, Switzerland) [37, 38]. To assess the parasite population structure, the genetic data was analysed with Structure 2.3.4 software, that assigned samples to different populations (K), and Structure Harvester was used to define the number of expected populations [39-41]. The data were evaluated using different $\mathrm{K}$ values $(K=1-15)$ and twenty independent repetitions were run for each $\mathrm{K}$ value with a burn-in period of 10,000 iterations followed by 1,000,000 iterations. In addition, software PHYLOViZ version 10 was used to construct a median-joining network diagram [42]. The samples were represented in a complete spanning tree using goeBURST algorithm. This analysis shows the possible evolutionary relationships between strains (samples) [42].

\section{Results}

Genetic characterization of Ecuadorian Plasmodium falciparum using neutral microsatellite markers

To determine the genetic composition of isolates from northwest Ecuador, Esmeraldas province, San Lorenzo county, between 2013 and 2016, seven neutral microsatellite markers located in six different chromosomes were genotyped. The markers showed the presence of different alleles. The marker TA1 had two alleles: the allele 171 , present in $90 \%$ of the samples $(37 / 41)$, and the allele 174 , present in $7 \%$ of the samples $(3 / 41)$. The marker Poly- $\alpha$ was one of the most diverse with five alleles: the allele 180 was the most common $(42 \%)$ in all the samples, while $34 \%$ of the samples $(14 / 41)$ had the allele 147 , the allele 183 was present in $15 \%$ of the samples (6/41) and the allele 174 was present in $7 \%$ (3/41) of the samples, the allele 177 was present in $2 \%$ $(1 / 41)$ of the samples. PfPK2 also had five alleles, being the most common 168 in $44 \%$ of the samples (18/41), $39 \%(16 / 41)$ of the samples had the allele $174,7 \%$ $(3 / 41)$ of the samples had the alleles 171 and 159 and $2 \%(1 / 41)$ had the allele 177 . The marker TA109 was the least diverse marker, with the allele 160 present in
Table 1 Number of alleles, heterozygosity (He) and linkage disequilibrium (LD) of $P$. falciparum in northwest Ecuador

\begin{tabular}{lllll}
\hline Groups & $\begin{array}{l}\text { Number } \\
\text { of samples }\end{array}$ & Number of alleles & He & LD $\left(\mathbf{I}_{\mathbf{A}}^{\mathbf{S}}\right)$ \\
\hline San Lorenzo & 41 & 3.6670 & 0.4726 & 0.0762 \\
Esmeraldas & 34 & 2.4000 & 0.1018 & 0.3798 \\
\hline
\end{tabular}

Table 2 Pairwise Fst of Ecuadorian, Peruvian [21] and Colombian samples [26]

\begin{tabular}{llll}
\hline Location & No. samples & Esmeraldas & San Lorenzo \\
\hline Esmeraldas (ECU) & 34 & 0.00000 & \\
San Lorenzo (ECU) & 41 & 0.39640 & 0.00000 \\
Zarumilla (PER) & 42 & 0.15103 & 0.29417 \\
West Amazon (PER) & 15 & 0.77968 & 0.35719 \\
Nariño (COL) & 34 & 0.45433 & 0.08481 \\
Valle (COL) & 25 & 0.46825 & 0.06966 \\
\hline
\end{tabular}

all the samples. The microsatellite 2490 showed three alleles, being the most common 81 in $56 \%(23 / 41)$ of the samples, 72 in $22 \%(9 / 41)$ of the samples and 78 in $15 \%(6 / 41)$ of the samples. The marker C2M34 had five alleles and the most common was 224 in $51 \%$ of samples $(21 / 41), 29 \%(12 / 41)$ had the allele 226 , the alleles 222 and 232 were present in 5\% (2/41) of the samples and the less common allele was 230 in $2 \%(1 / 41)$ of the samples. The marker C3M69 had two alleles, 90\% of samples (37/41) had the allele 140 and 7\% (3/41) of samples had the allele 122 .

San Lorenzo samples showed a higher heterozygosity $(\mathrm{He}=0.4726)$ than Esmeraldas $(\mathrm{He}=0.1018)$ [7] (Table 1) and Linkage Disequilibrium (LD) in San Lorenzo $\left(\mathrm{I}_{\mathrm{A}}^{\mathrm{S}}=0.0762, \mathrm{p}<1.00 \times 10^{-2}\right)$ was much lower than in Esmeraldas $\left(\mathrm{I}_{\mathrm{A}}^{\mathrm{S}}=0.3798, \mathrm{p}<1.00 \times 10^{-2}\right)$ [7] (Table 1). Pairwise Fst between the two Ecuadorian counties (Esmeraldas and San Lorenzo) was high (0.39640) [43] (Table 2).

Cluster analysis inferred a well differentiated population structure in this group of isolates. Three population clusters $(\mathrm{K})$ were predicted in northwest Ecuador (San Lorenzo and Esmeraldas) (Fig. 2). Most samples from San Lorenzo county 68.3\% (28/41) belonged to cluster one (Yellow); 24.4\% (10/41) belonged to cluster two (Red) and 7.3\% (3/41) belonged to cluster three (Pink) (Fig. 2). This information was confirmed by a Neighbour Joining network. Thirteen different haplotypes formed the yellow cluster, three haplotypes formed the red cluster, and two haplotypes were part of the pink cluster. 




Fig. 2 Population structure of Plasmodium falciparum samples from northwest Ecuador ( $N=75)$. SL: San Lorenzo County, ES: Esmeraldas County. Distribution of the three clusters (red, pink and yellow) across northwest Ecuador. San Lorenzo County had three clusters. Red-Cluster 1 ( $N=10$ ); Yellow—Cluster $3(\mathrm{~N}=28)$; Pink—Cluster $4(\mathrm{~N}=3)$. Esmeraldas County had three clusters. Red_Cluster $1(\mathrm{~N}=32)$; Yellow-Cluster $3(\mathrm{~N}=1)$; PinkCluster $4(\mathrm{~N}=1)$

\section{Genetic relatedness between Ecuadorian, Peruvian and Colombian isolates}

The comparison between Ecuadorian (2013-2016), Peruvian (1999-2012) [21] and Colombian (2003-2008) samples [26] showed close relationship between samples of the three countries. Pairwise Fst was performed between samples from northwest Ecuador and samples from neighboring locations of Peru and Colombia. Ecuadorian samples from San Lorenzo had a close genetic relationship with Valle (0.06966) and Nariño (0.08481) but were distantly related from the Peruvian West Amazon and the Pacific Coast of Peru (Table 2).

The comparison of localities using Structure software predicted the presence of four clusters in San Lorenzo, northwest Ecuador and its neighbouring locations. All samples (41/41) from San Lorenzo corresponded to three clusters (yellow, red and pink). The yellow cluster was predominantly present in Nariño [26], Colombia (35\%), the Red cluster was the most prevalent parasite in Esmeraldas (94\%), the pacific Coast of Peru [21] (71\%) and was present in Valle [26] (24\%) and the West Amazon of Peru [21] (13\%) (Fig. 3), while the pink cluster was predominant in Peru's West Amazon [21] (87\%), it was present in Nariño [26], Colombia (24\%), and in Esmeraldas [7] (3\%).

In order to identify if the parasites from northwest Ecuador corresponded to any of the previously reported clonal lineages or genetic clusters, a median-joining network was completed using predominant haplotypes of clonets D, E [21] and F [27]. The network diagram shows that $P$. falciparum from San Lorenzo's Yellow cluster are closely related to genetic lineage F from Colombia (two haplotypes shared with previously reported haplotype F) [27]. In addition, parasites in the Red cluster are closely related to E clonal lineage parasites present in Esmeraldas and previously in the North coast of Peru [7, 21]. Finally, parasites in the Pink cluster were related to clonal lineage $D$, first described in the Amazon of Peru and reported in 


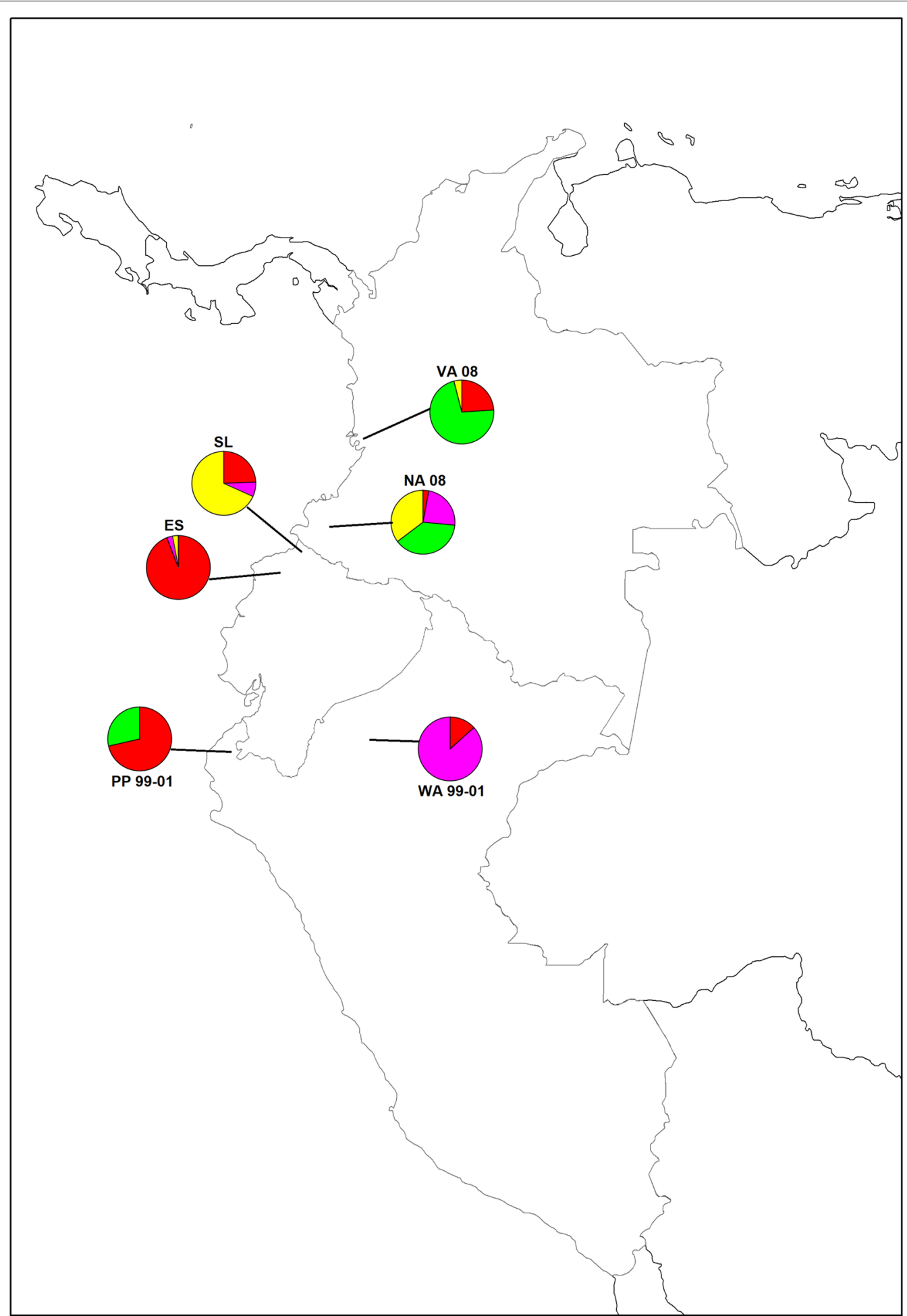

Fig. 3 Population structure of Plasmodium falciparum samples from Ecuador $(N=75)$, Colombia ( $N=59)$ [26] and Peru ( $N=57)$ [21]. SL: San Lorenzo County, ES: Esmeraldas County, VA: Valle, NA: Nariño, PP: Zarumilla, WA: West Amazon from Peru. Distribution of the four clusters across Ecuador, Colombia and Peru. Red—Cluster 1 ( $N=81)$; Green—Cluster $2(\mathrm{~N}=43)$; Yellow—Cluster $3(\mathrm{~N}=42)$; Pink—Cluster $4(\mathrm{~N}=25)$ 
Esmeraldas [7, 21] (Fig. 4). The main haplotypes for each previously described lineage and the parasites in this study are shown in Table 3.

\section{Discussion}

In Ecuador Plasmodium infections are reported in the Amazon and Costal regions [1, 7]. Specifically, the northwest coast of Ecuador has historically been endemic to $P$. falciparum where periodic transmission of this parasite at low levels has been reported [7]. This study was designed to understand the P. falciparum parasite population structure in parasite isolates collected in recent years and determine how this data can be used in support of malaria elimination efforts.

This study employed seven neutral microsatellites (TA1, Poly- $\alpha$, PfPK2, TA109, 2490, C2M34 and C3M69 $[12,18,33])$ to characterize $P$. falciparum populations from Esmeraldas Province in northwest Ecuador. The same seven markers have been widely used in South America to characterize $P$. falciparum populations in Peru [15, 21], Colombia [26, 27] and Brazil [44].

Plasmodium falciparum from northwest Ecuador have medium/low diversity (medium/low $\mathrm{He}$ and medium/ high linkage disequilibrium) similarly to what has been reported for other places of South America. This is partly because $P$. falciparum populations have undergone bottleneck events in the recent past due to elimination efforts by malaria programmes $[14,21,26]$.
When comparing San Lorenzo (border locality) with Esmeraldas (150 km from border), it is clear that the border locality has more diversity and has different genetic composition from less endemic localities. This is due to two main factors: (1) regular migration from Colombia is common in the border areas and (2) most samples collected in Esmeraldas city were from a clonal P. falciparum outbreak [7]. Low LD in border localities matches higher number parasites entering from Colombia into Ecuador and a higher number of cases in the border county of San Lorenzo [45, 46].

This study shows that northwest Ecuador has a simple, well defined structure. Indeed, between 2013 and 2016, three different genetic groups were present. These groups are related to previously reported groups in Colombia, Peru and Ecuador itself.

The majority of samples (68.3\%) had genetic similarity to samples circulating in Colombia. This cluster was previously defined as genetic lineage $\mathrm{F}$ by Dorado et al. [27]. The parasites in San Lorenzo, Ecuador shared the majority of markers with the defined F haplotype (Fig. 4 and Table 3) and only had some variations previously reported for F genetic lineage. This similarity is expected since the F clonet has been reported in the southern part of Colombia and human migration between Colombia and southern Ecuador is common. This human migration is related to several activities and some of the well-known include mining and palm oil agriculture. In addition, several Colombians and Ecuadorians cross the border on a

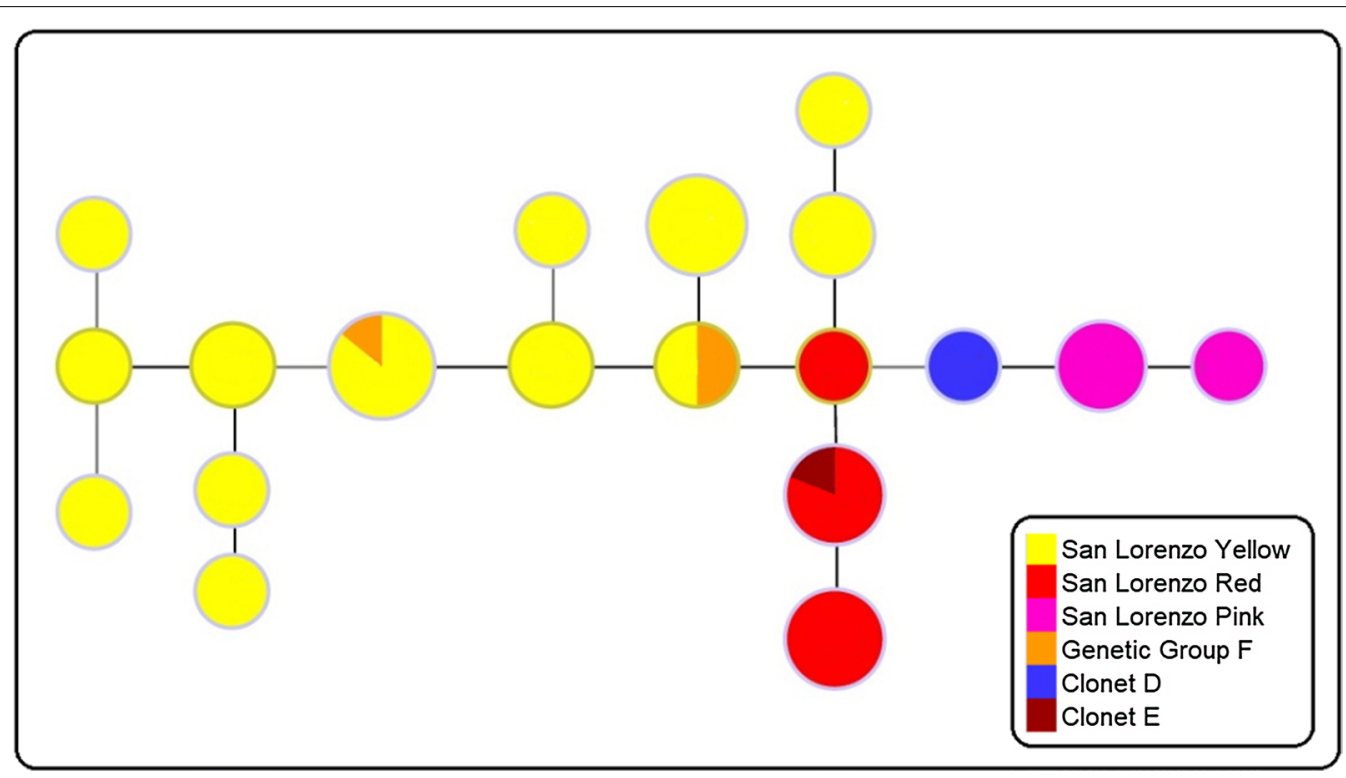

Fig. 4 Median-joining network diagram of Ecuadorian $P$. falciparum and previously reported clonets. The network diagram shows the genetic relationship between samples from San Lorenzo county, Esmeraldas county [7], Colombian genetic group F [27] and Peruvian clonets D and E [21]. The circle size is proportional to the number of samples with the same haplotype. The colors represent clusters assigned by Structure software 


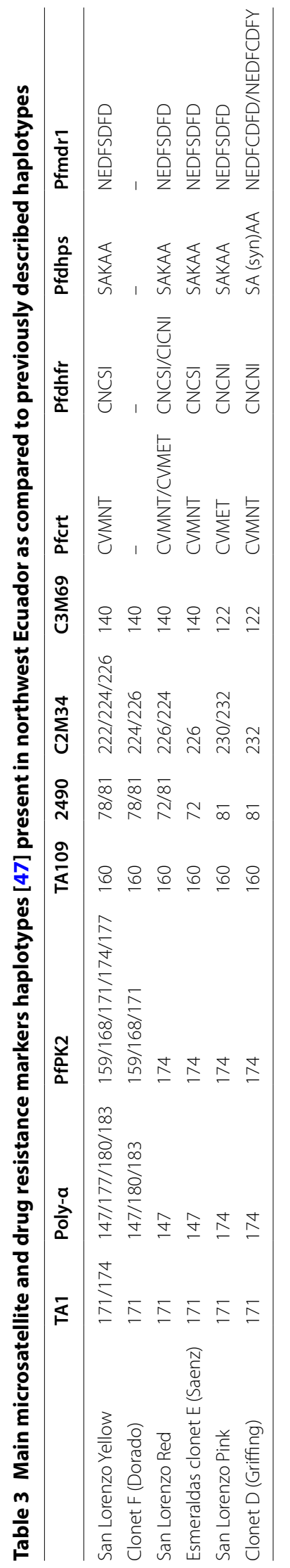


daily basis for other reasons. This genetic lineage presents the drug resistance haplotype CVMNT and wild type dhfr and dhps drug resistance markers. The mutations $184 \mathrm{~S}$ and 1042D in Pfmdr1 are also related to genotypes reported previously [47].

One-fourth (28\%) of the analysed samples from P. falciparum in San Lorenzo had genetic similarity or identity to parasites previously reported in an outbreak in Esmeraldas and the Pacific coast of Peru [7, 21]. This genetic type has also been reported in Valle, Colombia and in Nariño, Colombia with some variations. In addition, the E clonet was present in early 1990 in Esmeraldas province [7] suggesting that this group has been present in the area for several years. The parasites from clonet $\mathrm{E}$ have a characteristic conserved drug resistance genotype that includes a mutation in the 76 position of Pfcrt (CVMNT), prevalence of wild type genotypes for Pfdhfr and Pfdhps and mutations $184 \mathrm{~S}$ and 1042D in Pfmdr1 (Table 3) [7, 47].

A small percentage of the samples (7.3\%) have similarity with $\mathrm{D}$ clonal type previously reported in the West Amazon of Peru [21], Esmeraldas [7] and Colombia [27]. The D clonet was first reported in the West Amazon of Peru in 1999-2000 but found in the South Pacific Coast of Colombia in 2008 and in the Ecuadorian coast in 2013 $[7,21,26,27]$. The D clonet was found again in the north coast of Ecuador in this study in samples from 2013 and 2014 but not in more recent samples. As previously suggested by Griffing et al. [21], these clonal type parasites could have migrated to western Amazon of Peru from Ecuador which could have originated in Colombia and spread south to Ecuador [21]. The D clonet parasites in Ecuador have a characteristic pfcrt CVMET genotype and the synonymous mutation in the 540 position of pfdhps is common $[7,47]$.

In summary, this study showed that all the parasites that were found in the reported study sites clearly belonged to one of the three mentioned clusters that have been known to be present in the Pacific Coast of Peru, Ecuador and Colombia. It was difficult to determine if there are further variations between these clonal types found in Colombia, Ecuador and Peru using these limited genetic markers. However, future efforts can focus on characterizing the genotypes of these parasite types using genomic analysis. This data suggests that some ancestral populations that have been known to have existed in this region are still continuing to cause transmission of malaria in this region. Previous studies have also found that most of these parasites are carrying markers associated with CQ resistance but sensitive to SP. No evidence for artemisinin resistant genotypes were found. Collectively, these data suggest using current anti-malarial drug policies implemented in Ecuador these parasites can be treated during elimination phase. Continuous characterization of parasite isolates from this region using genomic analysis may help to determine if human migration between border regions of Ecuador and Colombia is a primary cause of malaria importation to Ecuador.

This study increases the knowledge about $P$. falciparum populations circulating in Ecuador and in the region. It gives a better understanding of the parasites present for future surveillance and prevention of parasite re-introduction in an area that is in the process of eliminating malaria. New outbreaks can be studied based on the current situation and new haplotypes can be easily identified.

\section{Conclusions}

The P. falciparum diversity found in Ecuador could be a product of migration or the result of haplotypes circulating in the country in low proportions. The three genetic groups present in the north coast of Ecuador confirm the low transmission situation of the last endemic area of the coast of the country. Studies of the genetic characterization of $P$. falciparum in eliminating areas help determine the possible origin of parasites in order to create strategies to prevent the entrance of new lineages and achieve local elimination of malaria.

\section{Abbreviations \\ AMOVA: analysis of molecular variance; $A R T$ : artemisinin; $\mathrm{BV}_{1}$ : genetic lineage $B V 1$ variant; $C Q$ : chloroquine; $\mathrm{EV}_{1}$ : genetic lineage $\mathrm{EV} 1$ variant; $F$ st: pairwise fixation indices; He: heterozygosity; K: number of genetic groups; LD: linkage disequilibrium; MQ: mefloquine; PET-PCR: photo-induced electron transfer polymerase chain reaction; QN: quinine; RDT: rapid diagnostic tests; SP: sulfadoxine-pyrimethamine.}

\section{Acknowledgements}

We thank Dr. Venkatachalam Udhayakumar for technical support and critically reviewing this manuscript. We would like to thank the personnel of the Ecuadorian Ministry of Public Health taking part in the sample collection and all the patients participating in this study.

\section{Authors' contributions}

FES conceived and designed the study; CVA and FS wrote the manuscript; CVA performed the experiments; LEC and JG-O performed field work. All authors read and approved the final manuscript.

\section{Funding}

This work was supported by PUCE grants L13058, L13248 and M13416 and the Global Infectious Diseases Training Grant-Fogarty International CenterNational Institutes of Health (D43TW008261), National Institutes of Health, USA.

\section{Availability of data and materials}

All data generated or analysed during this study are included in this published article (and its additional files).

\section{Ethics approval and consent to participate}

The protocol was approved by the Ethical Review Committee of Pontificia Universidad Católica del Ecuador (approvals \#: CBE-016-2013 and 20-11-1401). Written informed consent was provided by study participants and/or their legal guardians. 


\section{Consent for publication \\ Not applicable.}

\section{Competing interests}

The authors declare that they have no competing interests.

\section{Author details}

${ }^{1}$ Centro de Investigación para la Salud en América Latina, Facultad de Ciencias Exactas y Naturales, Pontificia Universidad Católica del Ecuador, Av. 12 de octubre 1076, Apartado: 17-01-2184, Quito, Ecuador. ${ }^{2}$ Ministerio de Salud Pública, Guayaquil, Ecuador. ${ }^{3}$ Ministerio de Salud Pública, Distrito de Salud de San Lorenzo, San Lorenzo, Ecuador.

Received: 4 February 2019 Accepted: 22 July 2019

Published online: 26 July 2019

\section{References}

1. WHO. World malaria report. Geneva: World Health Organization; 2017.

2. Yalcindag E, Elguero E, Arnathau C, Durand P, Akiana J, Anderson TJ, et al. Multiple independent introductions of Plasmodium falciparum in South America. Proc Natl Acad Sci. 2012;109:511-6.

3. WHO. World malaria report. Geneva: World Health Organization; 2016

4. WHO. World malaria report. Geneva: World Health Organization; 2015.

5. Bousema T, Drakeley C. Epidemiology and infectivity of Plasmodium falciparum and Plasmodium vivax gametocytes in relation to malaria control and elimination. Clin Microbiol Rev. 2011;24:377-410.

6. MSP. Gaceta Epidemiológica Semanal No. 52: Ministerio de Salud Pública del Ecuador. Quito: Ministerio de Salud Pública del Ecuador; 2017.

7. Saenz FE, Morton LC, Okoth SA, Valenzuela G, Vera-Arias CA, Velez-Alvarez E, et al. Clonal population expansion in an outbreak of Plasmodium falciparum on the northwest coast of Ecuador. Malar J. 2015;13:497.

8. Niang M, Thiam LG, Loucoubar C, Sow A, Sadio BD, Diallo M, et al. Spatiotemporal analysis of the genetic diversity and complexity of Plasmodium falciparum infections in Kedougou, southeastern Senegal. Parasit Vectors. 2017;10:33

9. Tibayrenc M, Ayala FJ. The clonal theory of parasitic protozoa: 12 years on. Trends Parasitol. 2002;18:405-10.

10. Landier J, Parker DM, Thu AM, Lwin KM, Delmas G, Nosten FH, et al. Effect of generalised access to early diagnosis and treatment and targeted mass drug administration on Plasmodium falciparum malaria in Eastern Myanmar: an observational study of a regional elimination programme. Lancet. 2018;391:1916-26.

11. Carter TE, Malloy H, Existe A, Memnon G, St Victor Y, Okech BA, et al. Genetic diversity of Plasmodium falciparum in Haiti: insights from microsatellite markers. PLOS ONE. 2015;10:e0140416.

12. Anderson TJ, Haubold B, Williams JT, Estrada-Franco JG, Richardson L, Mollinedo R, et al. Microsatellite markers reveal a spectrum of population structures in the malaria parasite Plasmodium falciparum. Mol Biol Evol. 2000;17:1467-82

13. Udhayakumar V, Barnwell JW, De Oliveira AM. Vigilancia molecular de la resistencia de Plasmodium falciparum a los antimaláricos (de 2005 a 2012). Atlanta: Centers for Disease Control and Prevention; 2013.

14. Echeverry DF, Nair S, Osorio L, Menon S, Murillo C, Anderson TJ. Long term persistence of clonal malaria parasite Plasmodium falciparum lineages in the Colombian Pacific region. BMC Genet. 2013;14:2.

15. Baldeviano GC, Okoth SA, Arrospide N, Gonzalez RV, Sanchez JF, Macedo $\mathrm{S}$, et al. Molecular epidemiology of Plasmodium falciparum malaria outbreak, Tumbes, Peru, 2010-2012. Emerg Infect Dis. 2015;21:797-803.

16. Arango EM, Samuel R, Agudelo OM, Carmona-Fonseca J, Maestre A, Yanow SK. Genotype comparison of Plasmodium vivax and Plasmodium falciparum clones from pregnant and non-pregnant populations in North-west Colombia. Malar J. 2012;11:392.

17. Larranaga N, Mejia RE, Hormaza Jl, Montoya A, Soto A, Fontecha GA. Genetic structure of Plasmodium falciparum populations across the Honduras-Nicaragua border. Malar J. 2013;12:354.

18. Anderson T, Su X-Z, Bockarie M, Lagog M, Day K. Twelve microsatellite markers for characterization of Plasmodium falciparum from finger-prick blood samples. Parasitology. 1999;119:113-25.
19. Moody A. Rapid diagnostic tests for malaria parasites. Clin Microbiol Rev. 2002;15:66-78.

20. Recht J, Siqueira AM, Monteiro WM, Herrera SM, Herrera S, Lacerda MVG. Malaria in Brazil, Colombia, Peru and Venezuela: current challenges in malaria control and elimination. Malar J. 2017:16:273.

21. Griffing SM, Mixson-Hayden T, Sridaran S, Alam MT, McCollum AM, Cabezas C, et al. South American Plasmodium falciparum after the malaria eradication era: clonal population expansion and survival of the fittest hybrids. PLoS ONE. 2011;6:e23486.

22. Sridaran S, Rodriguez B, Soto AM, De Oliveira AM, Udhayakumar V. Molecular analysis of chloroquine and sulfadoxine-pyrimethamine resistanceassociated alleles in Plasmodium falciparum isolates from Nicaragua. Am J Trop Med Hyg. 2014;90:840-5.

23. Cortese JF, Caraballo A, Contreras CE, Plowe CV. Origin and dissemination of Plasmodium falciparum drug-resistance mutations in South America. J Infect Dis. 2002;186:999-1006.

24. Chenet SM, Schneider KA, Villegas L, Escalante AA. Local population struc ture of Plasmodium: impact on malaria control and elimination. Malar J. 2012;11:412.

25. Chenet SM, Okoth SA, Kelley J, Lucchi N, Huber CS, Vreden S, et al. Molecular profile of malaria drug resistance markers of Plasmodium falciparum in suriname. Antimicrob Agents Chemother. 2017;61:e02655-16.

26. Solano CM, Okoth SA, Abdallah JF, Pava Z, Dorado E, Incardona S, et al. Deletion of Plasmodium falciparum histidine-rich protein 2 (pfhrp2) and histidine-rich protein 3 (pfhrp3) genes in Colombian parasites. PLoS ONE. 2015;10:e0131576.

27. Dorado EJ, Okoth SA, Montenegro LM, Diaz G, Barnwell JW, Udhayakumar $V$, et al. Genetic characterisation of Plasmodium falciparum isolates with deletion of the pfhrp2 and/or pfhrp3 genes in Colombia: the Amazon Region, a challenge for malaria diagnosis and control. PLOS ONE. 2016:11:e0163137.

28. Chenet SM, Taylor JE, Blair S, Zuluaga L, Escalante AA. Longitudinal analysis of Plasmodium falciparum genetic variation in Turbo, Colombia: implications for malaria control and elimination. Malar J. 2015;14:363.

29. Aponte S, Guerra ÁP, Álvarez-Larrotta C, Bernal SD, Restrepo C, González C, et al. Baseline in vivo, ex vivo and molecular responses of Plasmodium falciparum to artemether and lumefantrine in three endemic zones for malaria in Colombia. Trans R Soc Trop Med Hyg. 2017;111:71-80.

30. Orjuela-Sánchez P, Brandi MC, Ferreira MU. Microsatellite analysis of malaria parasites. Microsatellites: methods and protocols. Totowa: Humana Press; 2013. p. 247-58.

31. Snounou G. Detection and identification of the four malaria parasite species infecting humans by PCR amplification. Methods Mol Biol. 1996;50:263-91.

32. Lucchi NW, Narayanan J, Karell MA, Xayavong M, Kariuki S, DaSilva AJ, et al. Molecular diagnosis of malaria by photo-induced electron transfer fluorogenic primers: PET-PCR. PLOS ONE. 2013;8:e56677.

33. Abdallah JF, Okoth SA, Fontecha GA, Torres REM, Banegas El, Matute ML, et al. Prevalence of pfhrp2 and pfhrp3 gene deletions in Puerto Lempira, Honduras. Malar J. 2015;14:19.

34. McCollum AM, Mueller K, Villegas L, Udhayakumar V, Escalante AA. Common origin and fixation of Plasmodium falciparum dhfr and dhps mutations associated with sulfadoxine-pyrimethamine resistance in a low-transmission area in South America. Antimicrob Agents Chemother. 2007:51:2085-91.

35. Akinyi S, Hayden T, Gamboa D, Torres K, Bendezu J, Abdallah JF, et al. Multiple genetic origins of histidine-rich protein 2 gene deletion in Plasmodium falciparum parasites from Peru. Sci Rep. 2013;3:2797.

36. Biosystems A. Peak scanner software version 1.0 reference guide. Waltham: Thermo Fisher Scientific; 2006

37. Excoffier L, Lischer HE. Arlequin suite ver 3.5: a new series of programs to perform population genetics analyses under Linux and Windows. Mol Ecol Resour. 2010;10:564-7.

38. Schneider S, Roessli D, Excoffier L. Arlequin ver. 2.000. A software for population genetics data analysis. Geneva: Genetics and Biometry Laboratory, University of Geneva; 2000

39. Pritcharda JK, Wena X, Falushb D. Documentation for structure software: version 2.3. Waltham: Thermo Fisher Scientific; 2009.

40. Pritchard JK, Stephens M, Donnelly P. Inference of population structure using multilocus genotype data. Genetics. 2000;155:945-59. 
41. Earl DA. STRUCTURE HARVESTER: a website and program for visualizing STRUCTURE output and implementing the Evanno method. Conservation Genetics Resources. 2012;4:359-61.

42. Francisco AP, Vaz C, Monteiro PT, Melo-Cristino J, Ramirez M, Carriço JA. PHYLOViZ: phylogenetic inference and data visualization for sequence based typing methods. BMC Bioinformatics. 2012;13:87.

43. Wright S. Evolution and the genetics of populations. Chicago: Univerity of Chicago Press; 1978.

44. Griffing SM, Viana GMR, Mixson-Hayden T, Sridaran S, Alam MT, de Oliveira AM, et al. Historical shifts in Brazilian P. falciparum population structure and drug resistance alleles. PLoS ONE. 2013;8:e58984.
45. MSP. Gaceta Epidemiológica Semanal No. 31: Ministerio de Salud Pública del Ecuador. Quito: Ministerio de Salud Pública del Ecuador; 2018.

46. MSP. Reporte de Datos de Malaria del periodo 2008 al inicios del 2018 Quito: Ministerio de Salud Pública del Ecuador; 2018.

47. Valenzuela GR, P. Saenz, FE. Genotypes and phenotypes of resistance in Ecuadorian Plasmodium falciparum. Quito. 2018.

\section{Publisher's Note}

Springer Nature remains neutral with regard to jurisdictional claims in published maps and institutional affiliations.
Ready to submit your research? Choose BMC and benefit from:

- fast, convenient online submission

- thorough peer review by experienced researchers in your field

- rapid publication on acceptance

- support for research data, including large and complex data types

- gold Open Access which fosters wider collaboration and increased citations

- maximum visibility for your research: over $100 \mathrm{M}$ website views per year

At BMC, research is always in progress.

Learn more biomedcentral.com/submissions 